\title{
ANÁLISE DA DISTRIBUIÇÃO DAS QUEIMADAS NO CERRADO MARANHENSE, BRASIL (2014-2018)
}

\author{
ANALYSIS OF THE DISTRIBUTION OF FIRES IN THE SAVANNA OF MARANHÃO, \\ BRAZIL (2014-2018)
}

\author{
ANÁLISIS DE LA DISTRIBUCIÓN DE LAS QUEMAS EN LA SABANA DE MARANHÃO, \\ BRASIL (2014-2018)
}

\author{
Daniela Pinto Sales ${ }^{1}$ \\ Francisco Marques Oliveira Neto ${ }^{2}$
}

\begin{abstract}
Resumo
Através da análise da distribuição das queimadas no cerrado maranhense, esta pesquisa tem por objetivo mostrar os dados relativos às produzidas entre os anos de 2014 e 2018. Utilizaram-se fontes de dados pertinentes para o desenvolvimento da análise proposta. Observou-se que os níveis de queimadas, mesmo com uma redução significativa no ano de 2018, ainda são preocupantes, principalmente no bioma analisado, por conta do acelerado processo de antropização, do agronegócio e das secas. Podemos concluir que é necessário investir na prática de ações que conscientizem a todos da importância do Bioma Cerrado.
\end{abstract}

Palavras-chave: Cerrado. Maranhão. Queimadas.

\begin{abstract}
Through the analysis of the distribution of fires in the savanna of Maranhão, this research aims to show the data related to those produced between the years 2014 and 2018. Relevant data sources were used for the development of the proposed analysis. It was observed that the levels of fires, even with a significant reduction in 2018, are still worrisome, especially in the analyzed biome, due to the accelerated process of anthropization, agribusiness and droughts. We can conclude that it is necessary to invest in the practice of actions that make everyone aware of the importance of the savanna Biome.
\end{abstract}

Keywords: Savanna. Maranhão. Fires.

\section{Resumen}

Por medio del análisis de la distribución de las quemas en la sabana de Maranhão, esta investigación tiene el objetivo de estudiar los datos relativos a las producidas entre los años de 2014 y 2018 . Se utilizaron fuentes de datos pertinentes para el desarrollo del estudio propuesto. Se pudo observar que los niveles de las quemas, aun con una reducción significativa en el año 2018, todavía son preocupantes, sobre todo en el bioma analizado, por el acelerado proceso de antropización, del agronegocio y de las sequías. Se puede concluir que es necesario invertir en la práctica de acciones que generen consciencia colectiva sobre la importancia del bioma sabana.

Palabras-clave: Sabana. Maranhão. Quemas.

\section{Introdução}

O uso de fogo é uma ferramenta antiga utilizada para o manejo da agropecuária do Brasil. Esta prática primitiva pode ocorrer por meio de processos naturais ou como principal

\footnotetext{
${ }^{1}$ Doutorado Profissional em Defesa Sanitária Animal/UEMA. E-mail: daniela-psales@ hotmail.com

2 Mestre em Desenvolvimento e Meio Ambiente pelo Prodema vinculado a Universidade Federal do Piauí. E-mail: francisco.neto@ifma.edu.br.
} 
método de limpeza de área para plantio. $\mathrm{O}$ fogo é um importante agente evolutivo para as plantas e tem um papel importante na distribuição de savanas no mundo. Porém, as queimadas têm ocorrido nesse tipo vegetação há pelo menos 25 milhões de anos, provocando diversos malefícios e levando o solo à desertificação (SILVA et al., 2018).

No Maranhão, as queimadas têm se difundido amplamente, atingindo todos os biomas, inclusive as áreas de proteção e conservação. Gerude (2013), em sua pesquisa, detectou que, de 2008 a 2012, foram registrados 19.048 focos de calor nas Unidades de Conservação do Maranhão, correspondendo a $19,5 \%$ de todos os focos identificados no período.

O cerrado é um dos principais biomas maranhenses, apresenta um ambiente favorável para a expansão da fronteira agrícola e uma grande biodiversidade. Os avanços tecnológicos ocasionaram um agravamento na supressão e degradação deste bioma. O uso do fogo tem provocado ali alterações que resultam em perda de biodiversidade (RESENDE, 2017). Esta biodiversidade reflete em uma elevada riqueza de espécies, com plantas herbáceas, arbustivas, arbóreas e cipós, e uma diversa fauna com várias espécies de animais da região. Porém, apesar da elevada biodiversidade e de sua importância ecológica, várias espécies do cerrado encontram-se ameaçadas de extinção, pois este é considerado como um dos biomas mais ricos, mas também um dos mais ameaçados do mundo (MENDONÇA et al., 2008).

Dessa forma, esta pesquisa se propõe apresentar a distribuição das queimadas no Bioma Cerrado, no Estado do Maranhão, no período de 5 anos.

\section{2 Área de estudo}

O trabalho, como descrito anteriormente, analisará as queimadas no bioma cerrado, especificamente no estado do Maranhão.

O Maranhão é uma das 27 unidades federativas do Brasil; faz fronteira ao Norte com o Oceano Atlântico, ao Sul e Sudoeste com o estado do Tocantins, ao Oeste com o estado do Pará, e ao Leste com o estado do Piauí. Possui uma área de $331.937,450$ km², divididos entre 217 municípios, e sua capital é São Luís. Tem uma população estimada de 7.035 .055 pessoas até o ano de 2018, o que equivale aproximadamente a 19,81 hab $/ \mathrm{km}^{2}$, dados que fazem desse estado o segundo maior da região Nordeste e o oitavo maior do Brasil (IBGE, 2018).

Os tipos de vegetação presentes no estado são: floresta amazônica; cerrado; matas de cocais (babaçual); vegetação litorânea abrangendo o mangue, as dunas e a restinga; campos inundáveis e o carrasco (transição entre cerrado e caatinga). Eiten (1993, apud WALTER, 2006, p. 120), em suas pesquisas no Maranhão, constatou os seguintes tipos de vegetação: 
[...] cerrado (de várias fisionomias incluindo cerradão), floresta mesofítica, babaçual, buritizal (como parte ou não de vereda), carnaubal, campo úmido (campo limpo com gradação para brejo), brejos de graminóides, campos litossólicos (campos limpos sem a flora típica do cerrado) e vegetação de afloramento de rocha (que sustenta ou não flora de cerrado).

Conforme relatam Spinelli-Araujo et al. (2016), o Estado do Maranhão apresenta bioma cerrado em $64 \%$ do Estado, amazônia em 35\% e caatinga em 1\%. E 76\% do estado do Maranhão é considerado área de vegetação, $19 \%$ está protegido por unidades de conservação e menos de $5 \%$ pode ser considerado área de proteção integral, localizada fora do bioma amazônico e da Amazônia Legal. A figura abaixo apresenta as áreas de cobertura vegetal do Estado do Maranhão, segundo os dados do Instituto Maranhense de Estudos Socioeconômicos e Cartográficos - IMESC.

Figura 1: Remanescentes de Cobertura Vegetal no Estado do Maranhão

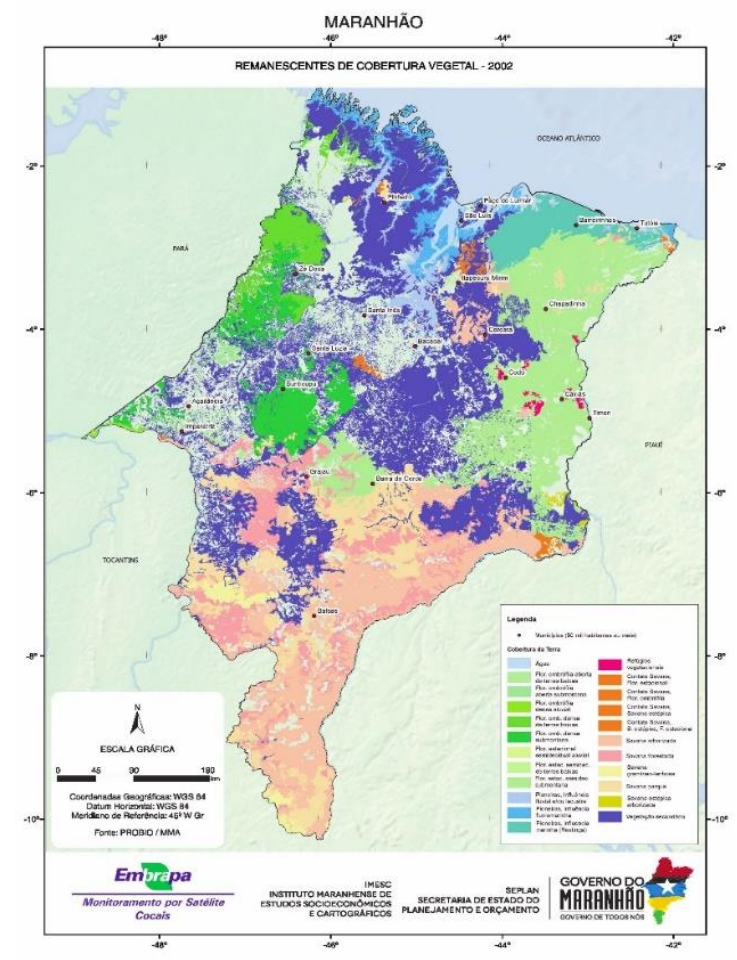

Fonte: IMESC (2002).

O bioma cerrado possui uma vasta quantidade de características particulares em seu território, como se demonstrou na figura 2: o campo limpo, o campo sujo, o cerrado 'sentido restrito', o cerradão, a mata seca, a mata de galeria e mata ciliar, o que enfatiza a sua diversificação estrutural e influi diretamente até na forma e nível de interferência antrópica (BRASIL, 2014). 


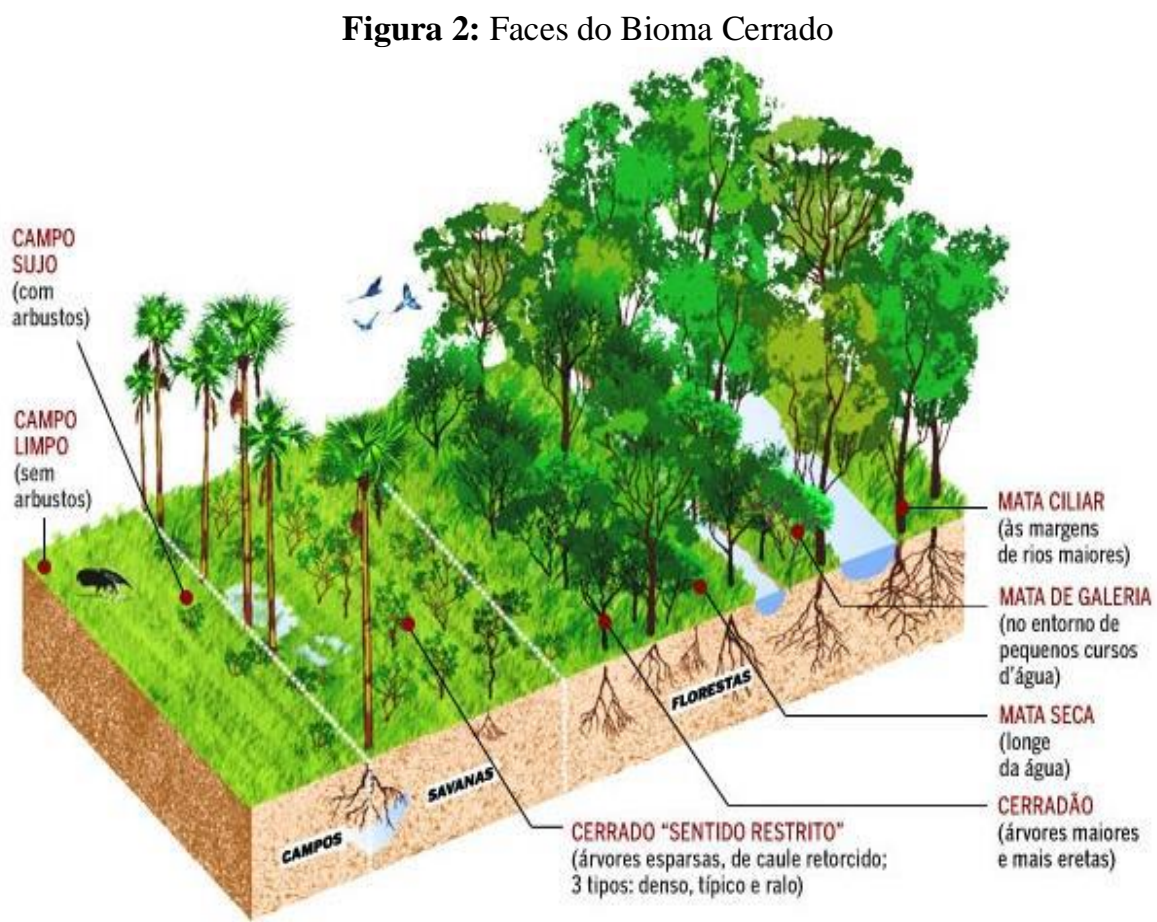

Fonte: (Brasil,2013).

Entre os tipos de vegetação presentes no Maranhão, o cerrado será o bioma analisado neste trabalho. Sendo considerado uma espécie de savana tropical da América do Sul, é o bioma com maior domínio florístico do Brasil, ocupando cerca de $24 \%$ de todo território nacional, o que equivale aproximadamente a 2.036.448 $\mathrm{km}^{2}$. É o segundo maior bioma brasileiro abrangendo o Distrito Federal, Bahia, Goiás, Mato Grosso, Mato Grosso do Sul, Minas Gerais, Paraná, Piauí, São Paulo, Tocantins e o Maranhão. Apresenta uma rica biodiversidade e uma variedade de paisagens (ARAÚJO; LOPES; CARVALHO, 2011; SILVA, FIGUEIREDO; ANDRADE, 2008; BRASIL, 2014).

No Maranhão, o cerrado é o bioma predominante; ocupa $65 \%$ de todo o seu território, ocorrendo em aproximadamente 33 municípios. É um dos biomas que atualmente sofrem grandes riscos devido ao agronegócio, ali principalmente da soja. Esse bioma conta com uma heterogeneidade nas suas formações por ser uma região ecotonal, com ocorrência de manchas de caatinga na sua porção leste, vegetação amazônica na região oeste e campos inundáveis na região central, além das restingas e manguezais, conforme figura abaixo (IMESC, 2002; SILVA; FIGUEIREDO; ANDRADE, 2008). 
Figura 3: Mapa dos biomas Amazônia Legal, Cerrado e Caatinga no Estado do Maranhão.

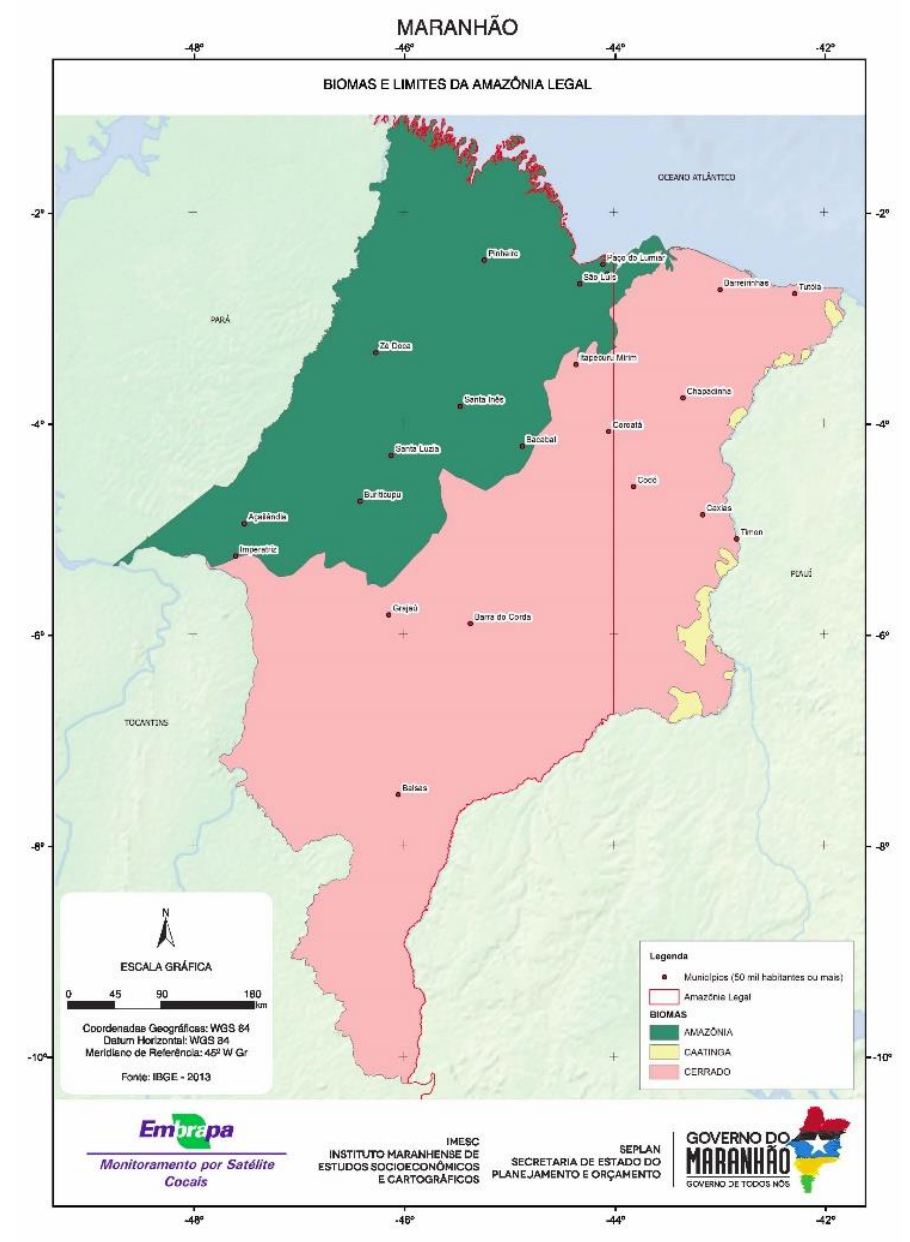

Fonte: IMESC (2002).

Segundo Silva et al. (2018), as queimadas ocorrem por meio de processos naturais ou por causas antrópicas, por mudanças na cobertura da terra e seu manejo. Estas a longo prazo podem ser altamente prejudiciais à terra, pois podem provocar a desertificação. No Brasil, o uso do fogo é uma prática comumente utilizada para a implantação e manejo de culturas agrícolas e para manutenção de pasto para gado. No ano de 2008 e 2012, foram registrados 19.048 focos de calor em unidades de conservação, correspondendo a $19,5 \%$ de todos os focos identificados no período para todo o Estado.

Dessa forma, este trabalho tem como objetivo apresentar o quadro de queimadas no bioma cerrado do Estado do Maranhão, 2014-2018.

\section{Materiais e métodos}

\subsection{Materiais utilizados}


Para captação dos dados que irão compor este trabalho, foram utilizados os produtos Moderate Resolution Imaging Spectroradiometer - MODIS, por conta de seu desempenho amplamente estudado quanto à detecção de áreas atingidas por queimadas em todo o território brasileiro, mais especificamente no bioma cerrado maranhense.

O MODIS é um instrumento desenvolvido pela NASA, um sensor considerado um dos componentes mais importantes das plataformas Terra e Aqua. Uma de suas principais funções é a de fornecer informações com dados específicos da superfície terrestre, dos oceanos e da atmosfera. Ele cobre toda superfície terrestre em aproximadamente dois dias, fornecendo informações relacionadas às regiões visíveis (VIS) e por infravermelho (IV) (LATORRE et al., 2003).

Também foram analisados dados do Programa Queimadas do INPE - que, por sua vez, foi a principal fonte de informações relacionadas com o tema deste trabalho-, do TerraBrasilis, que é uma plataforma criada pelo INPE com o intuito de organizar, facilitar o acesso e o uso de dados geográficos gerados pelos programas de monitoramento ambiental através de um portal web (INPE, 2019).

Consultaram-se também os dados disponibilizados pelo PRODES Cerrado, que elabora o mapeamento de todos os pontos onde foi constatado desmatamento no bioma estudado, além das plataformas do Instituto Brasileiro do Meio Ambiente e dos Recursos Naturais Renováveis - IBAMA, da Secretaria de Estado do Meio Ambiente e Recursos Naturais - SEMA, do Instituto Brasileiro de Geografia e Estatística - IBGE e várias outras fontes, as quais se usaram direta ou indiretamente na formulação dos gráficos com os dados coletados.

A pesquisa irá analisar o período de 2013 a 2018 relacionado às queimadas no território maranhense. Dessa forma o texto abaixo expõe de forma detalhada quais dados e de onde eles foram coletados para compor este trabalho.

\section{Resultados e discussão}

\subsection{Desmatamento}

A partir da década de 70, o cerrado brasileiro passou a ser alvo direto da exploração agrícola devido à necessidade de uma maior produção por conta do aumento das exportações agrícolas, que se tornou um dos maiores motivos para expansão do agronegócio no país e, consequentemente, do aumento do desmatamento no cerrado (PRODES, 2019). 
Araújo (2017, p. 9) esclarece que a "[...] monocultura de soja associada sempre a outras atividades, como a produção de carvão, indústria madeireira, pecuária, dentre outras, se intensificaram no Maranhão [...]”. A partir desse contexto, esse tipo de exploração só aumentou ao longo de vários anos, fazendo com que o bioma cerrado fosse o principal atingido no estado. Em decorrência do aumento do desmatamento no cerrado, o monitoramento é de suma importância para que a sua exploração desenfreada seja identificada e medidas cabíveis possam ser tomadas com maior êxito pelas autoridades competentes.

Uma série de medidas foram providenciadas; por exemplo, a criação do Plano de Ação para Prevenção e Controle do Desmatamento e das Queimadas no Cerrado - PPCerrado, em setembro de 2009, que deu origem a projetos desenvolvidos com o intuito de salvar esse bioma da antropização desenfreada, como o Projeto PRODES Cerrado.

Ao analisar a situação do estado do Maranhão quanto ao desmatamento no período analisado neste trabalho, dados preocupantes foram observados, constatando-se a iminente necessidade de uma maior fiscalização e posterior aplicação de ações que acabem ou diminuam a forma com que o bioma tem sido explorado.

No que diz respeito aos níveis de desmatamento no estado do Maranhão no período de 2014 a 2018, pode-se analisar a quantidade de quilômetros de cerrado desmatados através da Figura 4.

Figura 4: Desmatamento anual do Estado do Maranhão

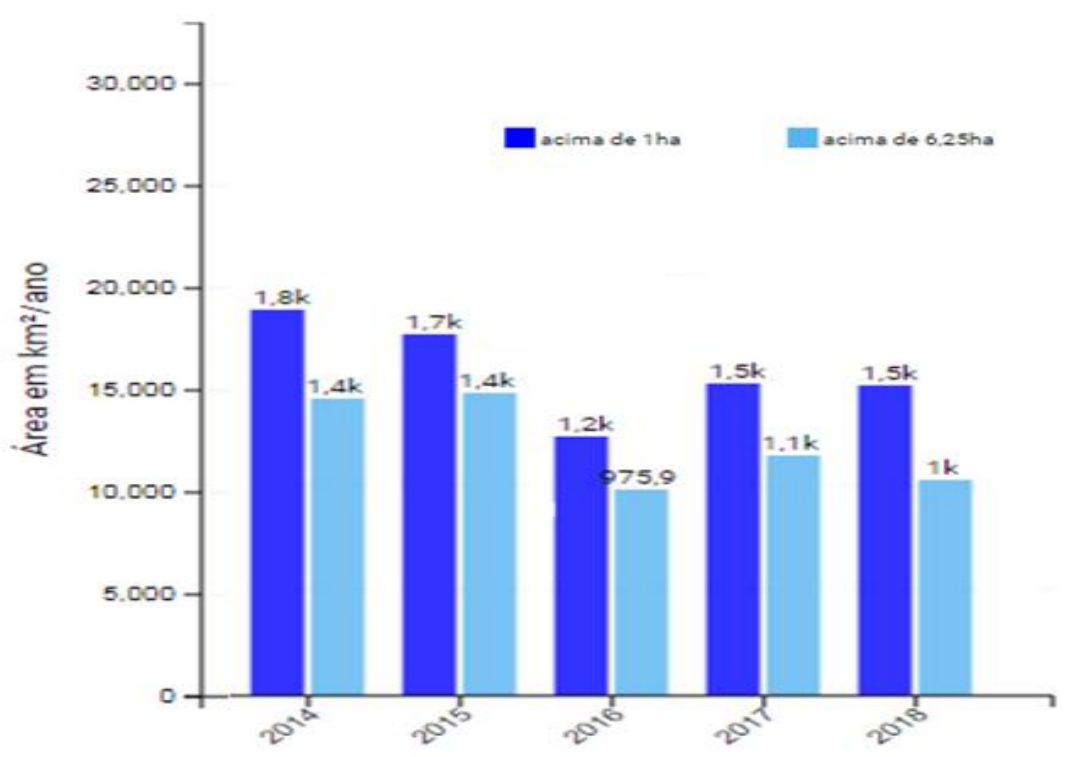

Fonte: Adaptado de (PRODES, 2019).

Através do mapeamento realizado pelo PRODES Cerrado, pode-se analisar a variação anual da área total desmatada no cerrado maranhense, exposta na Figura 4, onde se constata 
um total de 7.751,22 hectares desmatados no bioma cerrado, o que equivale a $17,8 \%$ dos estados em que o bioma pode ser encontrado (PRODES, 2019). Entre os cinco anos analisados, o ano que se destaca com relação aos quilômetros quadrados desmatados é o de 2014, quando houve desmatamento no cerrado maranhense em uma área de $1.837,25 \mathrm{~km}^{2}$.

Dentro do período analisado, os municípios que mais desmataram foram os descritos na Figura 5, onde se percebe que o município de Balsas, Grajaú e Riachão foram os que mais desmataram, com cerca de $588,41 \mathrm{~km}^{2}, 344,69 \mathrm{~km}^{2}$ e $290,74 \mathrm{~km}^{2}$ respectivamente.

Figura 5: Desmatamento nos Municípios do Maranhão

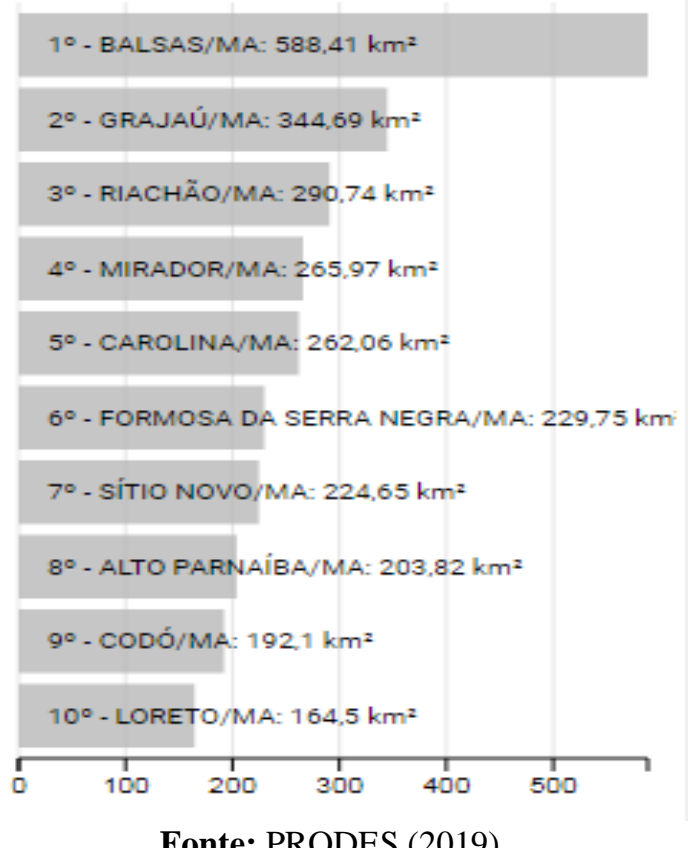

Fonte: PRODES (2019).

Segundo Rodrigues e Crispim (2002), o fogo está presente na atividade agropecuária, principalmente na região dos Cerrados e Amazônia, com o objetivo de promover a renovação ou recuperação das pastagens. Essa prática justifica-se pelo controle de plantas invasoras e maior oferta de forragem fresca e palatável para o gado, obtida através da emissão de brotações, proporcionada pela remoção da macega.

O fogo pode ser utilizado para diversas finalidades, como prevenção de incêndios, para a manutenção e construção de aceiros em áreas de plantio, queima de material enleirado, manejo de pastagens, da fauna silvestre e no controle de pragas e doenças (LIESENFELD; VIEIRA; MIRANDA, 2016). Porém, se não utilizado de maneira correta, pode destruir a vegetação nativa, cercas e propriedades vizinhas. Dessa forma, é de suma importância o investimento na prevenção das queimadas, tais como: construção de aceiros ao redor das áreas 
a serem queimadas ou ao redor das pastagens, das lavouras e das florestas que precisam ser protegidas do fogo (RESENDE, 2017).

\subsection{Clima}

A mudança climática é o maior desafio que a humanidade enfrenta nessas últimas décadas. Já sentimos seus efeitos; constitui um risco global, pois afeta a segurança climática, hídrica e alimentar e aumenta a vulnerabilidade social. As chuvas em excesso causam deslizamentos de terra, soterramento de casas, destruição de estradas, perdas de safras e de vidas humanas. E as secas prolongadas causam prejuízos na produção de alimentos, incêndios florestais e morte (DIAS, 2011).

Conforme relata o plano de ação para a prevenção e controle do desmatamento e das queimadas no estado do Maranhão (2011), a classificação climática acompanha a evolução das chuvas, e está relacionada com o índice pluviométrico anual e a demanda por evapotranspiração. Dessa maneira, no estado temos quatro tipos climáticos conforme a figura 6: Equatorial quente; Tropical Brasil Central; Tropical Zona Equatorial semiárido e Tropical Zona Equatorial semiúmido. Entre eles, os que estão presentes no cerrado maranhense são o Tropical Brasil Central, o Tropical Zona Equatorial semiárido e o Tropical Zona Equatorial semiúmido.O Maranhão apresenta uma grande extensão territorial, e sua localização geográfica como área de transição entre as regiões amazônica (úmida) e nordeste (semiárida) favorece grandes contrastes pluviométricos anuais conforme a figura 6 .

Figura 6: Divisão Climática e Precipitação anual do Estado do Maranhão.
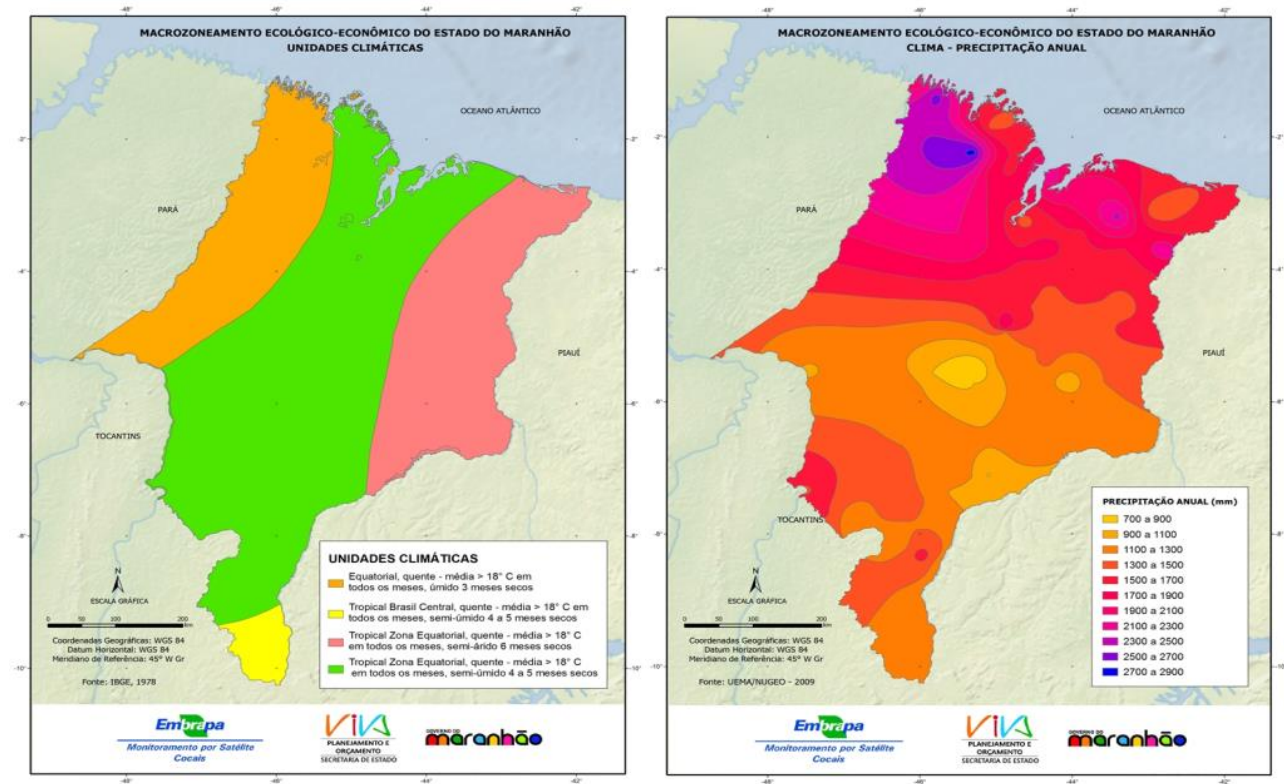

Fonte: Macrozoneamento ecológico-econômico do estado do Maranhão (MARANHÃO, 2011). 
Para enfrentar esse desafio, é necessário um conjunto de respostas adaptativas imediatas, por meio de cooperação entre diversos setores da sociedade (DIAS, 2011). Dessa forma, no período dos cinco anos analisados neste trabalho, as medições da seca no estado são cruciais para se observar os resultados das ações de antropização desenfreada do cerrado maranhense conforme demonstra a figura 7.

Figura 7: Histórico dos dados tabulares de seca do estado do Maranhão.

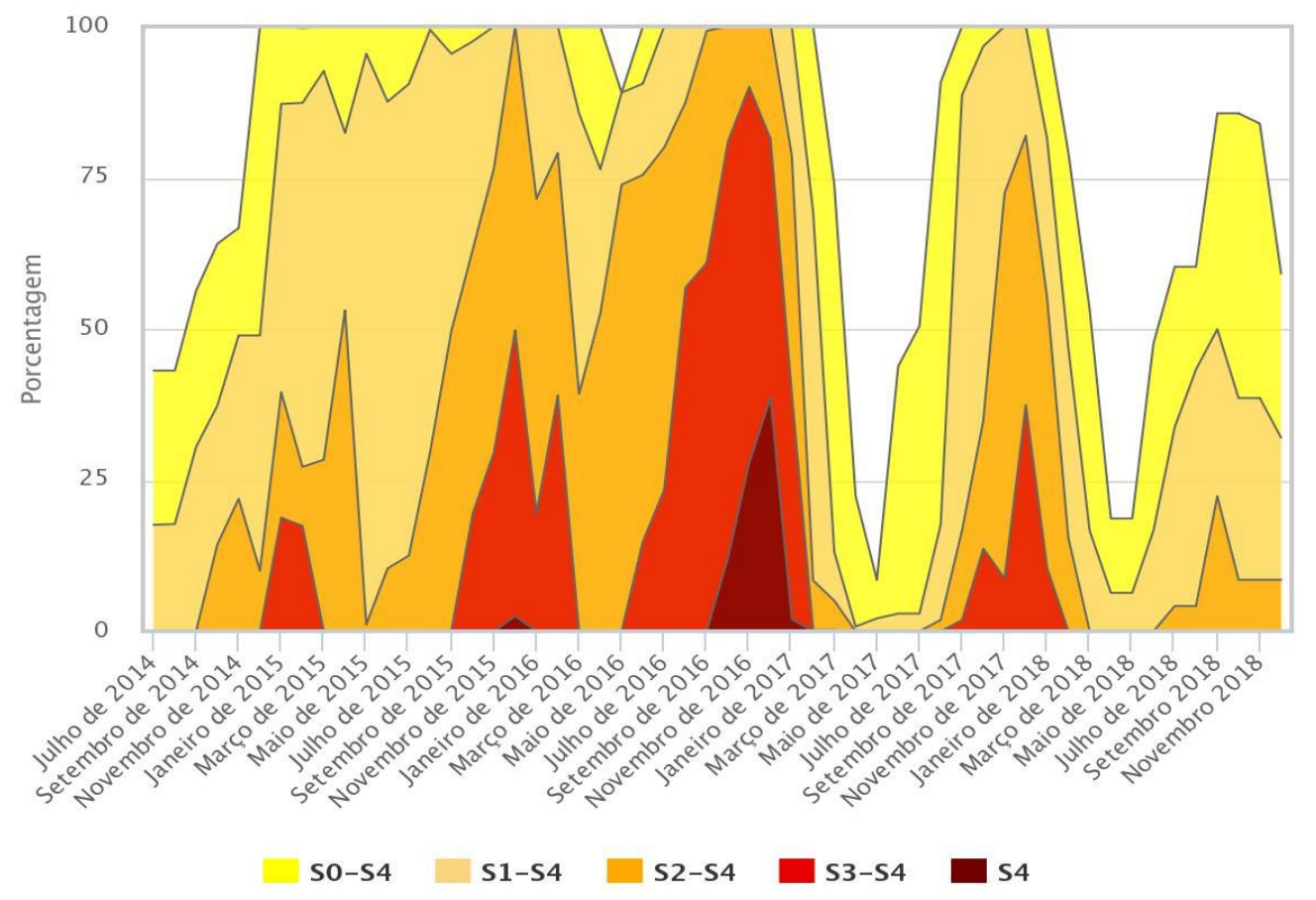

Fonte: Agência Nacional das Águas (ANA, 2018).

Nesse período podemos perceber que a intensidade da seca no estado passou por uma diminuição de S0 - Seca Fraca, S1 - Seca Moderada, S2 - Seca Grave, S3 - Seca Extrema e S4 - Seca Excepcional, para menos de $25 \%$ de seca grave, $50 \%$ seca moderada e mais de $75 \%$ de seca fraca no ano de 2018. Conforme Silva et al. (2017, p. 129) relatam, “(...) o período prolongado de secas no Maranhão, os focos de queimadas correspondem a um dos principais tensores ambientais que podem alterar a qualidade de vida humana, bem como biomas e ecossistemas maranhenses".

\subsection{Queimadas}

As queimadas representam grandes ameaças ao meio ambiente, prejuízos à saúde e ao ambiente; são um dos principais agressores do bioma cerrado. Elas surgem de forma espontânea, por queda de um raio, ou em consequência de alguma ação antrópica, seja ela 
acidental ou proposital (GERUDE, 2013). Além disso, essas queimadas que acompanham o desmatamento liberam gás carbônico $(\mathrm{CO} 2)$, metano $(\mathrm{CH} 4)$, monóxido de carbono $(\mathrm{CO})$ e nitroso de oxigênio (N2O). A parte da biomassa que não queima também será oxidada (FERNANDES; ARAÚJO; SILVA, 2017).

A probabilidade de que uma queimada surja no cerrado é muito alta se comparada com outros biomas como o amazônico, principalmente pelas suas altas temperaturas e pelo tipo de vegetação, características acrescidas por altas temperaturas devido a longos períodos de estiagem. Esses períodos são influenciados pelo fenômeno El Niño, que incide diretamente sobre algumas regiões do planeta e é responsável por variações extremas em relação ao clima habitual da região, como é o caso do cerrado (CUNHA et al., 2011).

No Maranhão, não é diferente; sendo um dos recordistas em focos de queimadas, todos os biomas presentes no estado são afetados sejam quais forem os motivos. Através do satélite de referência equipado com o Sensor MODIS, o INPE consegue copilar dados como os do Quadro 1, com a quantidade de todos os focos ativos detectados no estado entre os anos de 2014 a 2018.

Quadro 1: Série histórica do total de focos ativos detectados pelo satélite de referência, no período de janeiro de

\begin{tabular}{|c|c|c|c|c|c|c|c|c|c|c|c|c|c|}
\hline Ano & Jan. & Fev. & Mar. & Abr. & Maio & Jun. & Jul. & Ago. & Set. & Out. & Nov. & Dez. & Total \\
\hline $\mathbf{2 0 1 4}$ & $\mathbf{2 9 1}$ & $\mathbf{1 7}$ & $\mathbf{4 0}$ & $\mathbf{6 6}$ & $\mathbf{1 4 0}$ & $\mathbf{7 8 6}$ & $\mathbf{2 0 2 7}$ & $\mathbf{5 3 3 8}$ & $\mathbf{4 3 5 8}$ & $\mathbf{5 5 7 5}$ & $\mathbf{3 7 1 0}$ & $\mathbf{2 3 2 9}$ & $\mathbf{2 4 6 7 7}$ \\
\hline $\mathbf{2 0 1 5}$ & 460 & $\mathbf{7 8}$ & $\mathbf{4 1}$ & $\mathbf{1 0 3}$ & $\mathbf{1 8 4}$ & $\mathbf{8 5 0}$ & $\mathbf{1 6 1 6}$ & $\mathbf{5 4 1 2}$ & $\mathbf{5 5 0 3}$ & $\mathbf{6 3 8 7}$ & 4159 & $\mathbf{3 6 4 7}$ & $\mathbf{2 8 4 4 0}$ \\
\hline $\mathbf{2 0 1 6}$ & $\mathbf{3 9 6}$ & $\mathbf{2 6 8}$ & $\mathbf{7 0}$ & $\mathbf{1 0 3}$ & $\mathbf{1 8 6}$ & $\mathbf{6 9 3}$ & $\mathbf{2 1 8 2}$ & $\mathbf{3 8 4 9}$ & $\mathbf{3 1 1 0}$ & $\mathbf{5 6 1 7}$ & $\mathbf{3 8 2 7}$ & $\mathbf{1 4 9 4}$ & $\mathbf{2 1 7 9 5}$ \\
\hline $\mathbf{2 0 1 7}$ & $\mathbf{1 7 8}$ & $\mathbf{4 4}$ & $\mathbf{3 2}$ & $\mathbf{9 0}$ & $\mathbf{1 5 7}$ & $\mathbf{6 4 4}$ & $\mathbf{1 9 7 3}$ & $\mathbf{3 0 0 1}$ & $\mathbf{9 2 4 4}$ & $\mathbf{4 5 3 9}$ & $\mathbf{2 7 0 7}$ & $\mathbf{2 9 7 0}$ & $\mathbf{2 5 5 7 9}$ \\
\hline $\mathbf{2 0 1 8}$ & $\mathbf{2 8 1}$ & $\mathbf{1 5}$ & $\mathbf{9 3}$ & $\mathbf{5 0}$ & $\mathbf{2 0 3}$ & $\mathbf{7 3 8}$ & $\mathbf{1 4 5 7}$ & $\mathbf{2 8 3 3}$ & $\mathbf{3 1 7 8}$ & $\mathbf{1 8 3 2}$ & $\mathbf{2 3 0 9}$ & $\mathbf{9 0 4}$ & $\mathbf{1 3 8 9 3}$ \\
\hline Máx. & $\mathbf{4 6 0}$ & 268 & $\mathbf{9 3}$ & $\mathbf{1 0 3}$ & $\mathbf{2 0 3}$ & $\mathbf{8 5 0}$ & $\mathbf{2 1 8 2}$ & $\mathbf{5 4 1 2}$ & $\mathbf{9 2 4 4}$ & $\mathbf{6 3 8 7}$ & $\mathbf{4 1 5 9}$ & $\mathbf{3 6 4 7}$ & 33008 \\
\hline Méd. & 321,2 & 84,4 & 55,2 & 82,4 & 174 & 742,2 & 1851 & 4086,6 & 5078,6 & 4790 & 3342,4 & 2268,8 & 22876,8 \\
\hline Mín. & $\mathbf{1 7 8}$ & $\mathbf{1 5}$ & $\mathbf{3 2}$ & $\mathbf{5 0}$ & $\mathbf{1 4 0}$ & $\mathbf{6 4 4}$ & $\mathbf{1 4 5 7}$ & $\mathbf{2 8 3 3}$ & $\mathbf{3 1 1 0}$ & $\mathbf{1 8 3 2}$ & $\mathbf{2 7 0 7}$ & $\mathbf{9 0 4}$ & $\mathbf{1 3 8 9 3}$ \\
\hline
\end{tabular}

Fonte: Instituto Nacional de Pesquisas Espaciais - INEP (2018).

No cerrado brasileiro, entre os anos de 2014 a 2018, foram detectados cerca de 756.130 focos de incêndio, dos quais cerca de 114.384 foram registrados por satélite no estado do Maranhão; o que foi consumido pelas chamas apenas no bioma cerrado no estado equivale a $15,13 \%$ de toda área que foi atingida pelo fogo, em todo o território nacional, no bioma especificado.

Dados estes alarmantes, principalmente quando somados às alterações drásticas que o estado sofre em seu período de seca (de julho até meados de dezembro), que atinge seu ápice 
entre os meses de julho e outubro, com altíssimas temperaturas e precipitação pluviométrica abaixo de um nível aceitável. No Quadro 1 se pode observar a difícil situação ocorrida entre os anos de 2015 e 2017. Nesse período, houve uma grande seca no estado, que causou grandes perdas para todos os biomas, para a agropecuária, para os habitantes das regiões afetadas por elevar os riscos para a vida humana, entre vários outros fatores -, sem contar a intensificação das queimadas (MARTINS; MAGALHÂES; FONTENELE, 2017; SILVA et al., 2017).

Dos 114. 384 focos registrados no período de 2014-2018 no estado do Maranhão, o ano de 2014 equivale a $25 \%$ de todo período analisado, o que faz dele o ano com maior número de focos de incêndio; já em 2018 foram constatados 12\%, equivalentes a 13.893 focos, que representam uma queda de $13 \%$ no período em consideração.

Observa-se uma precipitação acumulada com níveis abaixo de $100 \mathrm{~mm}$, umidade relativa do ar abaixo de $70 \%$ e temperaturas superiores a $34^{\circ} \mathrm{C}$, de maneira que é inevitável o surgimento de focos de queimada; além de tantas características propicias para o fogo, é preciso tomar em consideração que o período de seca no estado chega a durar seis meses (SILVA, FIGUEIREDO; ANDRADE, 2008). Ou seja, o cerrado maranhense tem as condições ideais para o surgimento deste tipo de evento, sem contar a sua vegetação, que naturalmente é propícia ao fogo.

\section{Conclusão}

Através deste trabalho, pode-se observar a importância do bioma cerrado, não apenas para o estado do Maranhão - que foi a área estudada —, mas para todo o Brasil, tanto pela riqueza de sua biodiversidade, que o interliga aos demais biomas do país, quanto por sua contribuição para diversos aquíferos, para a economia e para o homem - através de sua fauna e flora, assim como por seu potencial para atividades que necessitem do uso do solo, como a agronomia e a agropecuária, por exemplo-.

Entretanto, o processo de antropização acelerado do cerrado maranhense, principalmente por conta da expansão de culturas agrícolas como a da soja e do milho, tem mudado a paisagem do cerrado em muitos municípios, muitas vezes de forma irreversível. Este crescimento contribui diretamente para o aumento do número de focos de queimadas, por ser a forma mais econômica de preparar o solo para o plantio.

Concluímos que é preciso que o governo modifique a maneira de educar as pessoas sobre formas de manejo que não agridam tanto o bioma cerrado para pôr fim às queimadas 
irregulares; que aplique a legislação existente para punir os infratores com mais rigidez. Mas, ainda assim, há muito que ser feito tanto em ações que transformem a forma com que os produtores rurais interagem com o solo, como em medidas que venham a controlar as queimadas, seja nos períodos de estiagem típicos da região estudada, como nos períodos de seca que eventualmente assolam o Cerrado Maranhense. É necessário que o uso consciente do fogo seja uma ferramenta e não um elemento agressor do cerrado.

\section{Referências}

ANA (Agência Nacional das Águas). Monitor de secas. 2018. Disponível em: http://monitordesecas.ana.gov.br. Acesso em: 28 mai. 2019

ARAÚJO, Elienê Pontes de; LOPES, Jucivan Ribeiro; CARVALHO FILHO, Raimundo. Aspectos socioeconômicos e de evolução do desmatamento na Amazônia maranhense. In: MARTINS, Marlúcia Bonifácio; OLIVEIRA, Tadeu Gomes de (org.). Amazônia maranhense: diversidade e conservação. Belém: MPEG, 2011. p. 35-46.

ARAÚJO, F. E. O desenvolvimento no Maranhão: Aspectos da expansão do capital no campo. In: JORNADA INTERNACIONAL DE POLÍTICAS PÚBLICAS, 8., 2017, São Luís. Anais [...]. São Luís, MA: UFMA, 2017.

BRASIL. IBGE. Mapa de biomas do Brasil: escala 1:5.000.000. 2004. Disponível em: http://mapas.ibge.gov.br/biomas2/viewer.htm. Acesso em: 20 dez. 2018.

BRASIL. Empresa Brasileira de Pesquisa Agropecuária (EMBRAPA). Satélites de Monitoramento. Brasil: EMBRAPA, 2013.

BRASIL. Ministério do Meio Ambiente (MMA). Plano de ação para prevenção e controle do desmatamento e das queimadas no Cerrado: $2^{\text {a }}$ fase (2014-2015) - PPCerrado. Brasília: MMA, 2014. 132 p.

CUNHA, Gilberto Rocca da et al. Niño/La Niña - Oscilação Sul e seus impactos na agricultura brasileira: fatos, especulações e aplicações. Revista Plantio Direto, Passo Fundo, RS, n. 121, p. 1-7, fev. 2011. Disponível em:

https://ainfo.cnptia.embrapa.br/digital/bitstream/item/53594/1/elnino.pdf. Acesso em: 28 mai. 2019.

DIAS, G. F. Fogo no clima: queimadas, incêndios florestais e mudança climática: subsídios para a educação ambiental. Brasília: Ibama, 2011.

FERNANDES, T. G.; ARAUJO, M. K.; SILVA, H. A. P. A educação no campo: as práticas das queimadas para a limpeza do solo e a conscientização ambiental na cidade de serra do Mel-RN. Revista Includere, Mossoró, RN, v. 3, n. 1, p. 422-436, 2017.

GERUDE, R. G. Focos de queimadas em áreas protegidas do Maranhão entre 2008 e 2012. In: SIMPÓSIO BRASILEIRO DE SENSORIAMENTO REMOTO, 16., 2009, Foz do Iguaçu. Anais [...]. Foz do Iguaçu: INPE, 2013. 
IMESC. Instituto Maranhense de Estudos Socioeconômicos e Cartográficos (Maranhão). Remanescentes de cobertura vegetal. São Luís, MA: EMBRAPA, fotografia aérea, 2002.

LATORRE, Marcelo Lopes; ANDERSON, L. O.; SHIMABUKURO, Yosio Edemir; CARVALHO JÚNIOR, Osmar Abílio de. Sensor MODIS: características gerais e aplicações. Espaço \& Geografia, Brasília, v. 6, n. 1, p. 91-121, 2003.

LIESENFELD, Marcus Vinicius de Athaydes; VIEIRA, Gil; MIRANDA, Ires Paula de Andrade. Ecologia do fogo e o impacto na vegetação da Amazônia. Brazilian Journal of Forestry Research, Colombo, v. 36, n. 88, p. 505-517, out./dez., 2016. (Pesquisa Florestal Brasileira).

MARANHÃO. Secretaria de Estado do Meio Ambiente e Recursos Naturais. Plano de ação para prevenção e controle do desmatamento e das queimadas no estado do Maranhão. (Decreto $n^{\circ}$ 27.317, de 14 de abril de 2011). São Luis, Maranhão: Grupo Permanente de Trabalho Interinstitucional, 2011. Disponível em:

http://www.fundoamazonia.gov.br/export/sites/default/pt/.galleries/documentos/prevencao-econtrole-do-desmatamento/Plano_Estadual_Maranhao.pdf. Disponível em: 28 abr. 2019.

MARTINS, E. S. P. R.; MAGALHÃES, A. R.; FONTENELE, D. A seca plurianual de 20102017 no Nordeste e seus impactos. Parcerias Estratégicas, Brasília DF, v. 22, n. 44, p. 17 40, jun. 2017. Disponível em:

http://seer.cgee.org.br/index.php/parcerias_estrategicas/article/viewFile/844/772. Acesso em: 28 mai. 2019.

MENDONÇA, R. C.; FELFILI, J. M.; WALTER, B. M. T.; SILVA JÚNIOR, M. C.; REZENDE, A. B.; FILGUEIRAS, T. S.; NOGUEIRA, P. E.; FAGG, C. W. Flora vascular do Bioma Cerrado: checklist com 12.356 espécies. In: SANO, S. M.; ALMEIDA, S. P.; RIBEIRO, J. F. (org.) Cerrado: ecologia e flora. Volume 2. Brasília: Embrapa Cerrados, p. 213-228, 2008.

PRODES. Instituto Nacional de Pesquisas Espaciais (INPE). Coordenação Geral de Observação da Terra. PRODES, 2019:incremento anual de área desmatada no Cerrado Brasileiro. 2019.Disponível em: http://www.obt.inpe.br/cerrado. Acesso em: 20 dez. 2019.

RESENDE, Fernanda Cristina. Análise da distribuição espacial das áreas queimadas na porção nordeste do bioma cerrado. 110 f. 2017. Dissertação (Mestrado do Programa de Pós-Graduação em Geografia) - Universidade Federal de São João Del Rei, São João Del Rei, 2017.Disponível em: https://www.ufsj.edu.br/portal2-repositorio/File/ppgeog/Fernanda.pdf. Aceso em: 28 mai. 2019.

RODRIGUES, Cristina Aparecida Gonçalves; CRISPIM, Sandra Mara Araújo; Comastri Filho, José Aníbal. Documentos 35: Queima controlada no Pantanal. Corumbá: Embrapa Pantanal, 2002. Acesso em: https://www.infoteca.cnptia.embrapa.br/bitstream/doc/810723/1/DOC35.pdf. Acesso em: 28 jun. 2019. 
SEMA. Secretaria de Estado do Meio Ambiente e Recursos Naturais (Maranhão).

Queimadas. 2018. Disponível em: http://www.sema.ma.gov.br/conteudo?/425/Queimadas. Acesso em 05 jan. 2019.

SILVA, H. G; FIGUEIREDO, N.; ANDRADE, G. V. Estrutura da vegetação e padrões de diversidade de um cerradão no nordeste do Maranhão. Revista Árvore, Viçosa MG, v. 32, n. 5, p. 921-930, 2008.

SILVA JUNIOR, Celso Henrique Leite; ANDERSON, Liana Oighenstein; ARAGÃO, Luiz Eduardo Oliveira e Cruz de; RODRIGUES, Bruno Durão. Dinâmica das queimadas no cerrado do Estado do Maranhão, Nordeste do Brasil. Revista do Departamento de Geografia, USP São Paulo, v. 35, p. 1-14, 2018. DOI: https://doi.org/10.11606/rdg.v35i0.142407.

SILVA, Nicodemus da Silva et al. A seca no Maranhão no período de 2010 a 2016 e seus impactos. Parcerias Estratégicas, Brasília DF, v. 22, n. 44, p. 119-138, jan./jun. 2017. Disponível em:

http://seer.cgee.org.br/index.php/parcerias_estrategicas/article/viewFile/848/776. Acesso em: 28 mai. 2019.

SPINELLI-ARAUJO, Luciana et al. Documentos 108: conservação da biodiversidade do Estado do Maranhão: Cenário atual em dados geoespaciais. Jaguariúna: Embrapa Meio Ambiente, 2016. 28 p.

WALTER, Bruno Machado Teles. Fitofisionomias do bioma Cerrado: síntese terminológica e relações florísticas. 2006. 388 f. Tese (Doutorado em Ecologia) - Universidade de Brasília, Brasília, 2006. DOI: https://repositorio.unb.br/handle/10482/3086. 